\title{
Using Experiential Learning to Enhance Student Outcomes in a Didactic Program in Dietetics Foodservice Management Course
}

\author{
Michael T. Holik \\ West Chester University of Pennsylvania, mholik@wcupa.edu \\ Scott Heinerichs \\ West Chester University of Pennsylvania, sheinerichs@wcupa.edu \\ Jena Wood \\ West Chester University of Pennsylvania, jenamarierd@gmail.com
}

Follow this and additional works at: https://nsuworks.nova.edu/ijahsp

Part of the Dietetics and Clinical Nutrition Commons, and the Education Commons

\begin{abstract}
Recommended Citation
Holik MT, Heinerichs S, Wood J. Using Experiential Learning to Enhance Student Outcomes in a Didactic Program in Dietetics Foodservice Management Course. The Internet Journal of Allied Health Sciences and Practice. 2021 Jan 01;19(1), Article 15.
\end{abstract}

This Manuscript is brought to you for free and open access by the College of Health Care Sciences at NSUWorks. It has been accepted for inclusion in Internet Journal of Allied Health Sciences and Practice by an authorized editor of NSUWorks. For more information, please contact nsuworks@nova.edu. 


\title{
Using Experiential Learning to Enhance Student Outcomes in a Didactic Program in Dietetics Foodservice Management Course
}

\begin{abstract}
Purpose: The purpose of this study was to describe student perceptions of their learning following experiential learning (EL) activities in a foodservice management course. Nutrition and dietetics education programs have a range of competencies students must learn and demonstrate throughout their curriculum. Learning styles differ amongst students and research has demonstrated they prefer to engage in EL (direct experience) activities to develop their knowledge. Foodservice management is one area of the curriculum that teaches students the basic functions of management; planning, organizing, directing, controlling, and staffing related to food, materials, facilities, and human resources. While this can be taught didactically, engaging in EL for this content may be a more valuable form of pedagogy to improve student understanding and use of content. Methods: After undergoing review and gaining approval from the Institutional Review Board, 196 nutrition and dietetic students from a regional comprehensive institution with an accredited undergraduate didactic program in dietetics were invited to participate in two experiential learning activities. At the conclusion of the activities, students completed an 8-question survey of their experiences. Results: Over $88 \%$ of students agreed EL activities promote better understanding of course content and $90 \%$ of students were in agreement that EL activities create an environment conducive to applying theory. Additionally, over $81 \%$ of students agreed that the activities encouraged the utilization of critical thinking skills, and $76 \%$ believed the activities promoted the value of teamwork and working independently. Finally, students were asked to respond to how the EL activity helped them understand course content and objectives. Two predominate themes emerged in the review of the openended responses. The first, EL helped connect and reinforce didactic theory to the real world ultimately assisting students to better prepare themselves for their career. The second focused on learning styles and students' appreciation for the non-traditional way of learning, outside the classroom, with hands-on application. Conclusions: The results of the study provide support for the use of EL activities in foodservice management courses in a dietetics program. Participation in EL activities helped students close the loop between theoretical and applied learning. EL helped the development and utilization of skills employers are seeking such as critical thinking, teamwork, and independence. EL allows students to be hands-on in their learning and engage in activities aligned with theory and content necessary to meet competencies for entry-level practice in the field. Future research should include other types of foodservice establishments where a registered dietitian nutritionist is employed to determine if those environments have a positive impact on student learning.
\end{abstract}

\section{Author Bio(s)}

Michael T. Holik, Ed.D., MS.Ed., is an Assistant Professor in the Department of Nutrition and Dietetics in the College of Health Sciences at West Chester University of Pennsylvania.

Scott Heinerichs, Ed.D., AT., is a Dean of the College of Health Sciences and Athletic Trainer at West Chester University of Pennsylvania.

Jena Wood, MS., RDN, LDN, is a Registered Dietitian Nutritionist and Adjunct at West Chester University. Jena is also a licensed Dietitian Nutritionist in the state of Pennsylvania. 


\title{
1IJAHSP \\ The Internet Journal of Allied Health Sciences and Practice \\ Dedicated to allied health professional practice and education
}

Vol. 19 No. 1 ISSN 1540-580X

\section{Using Experiential Learning to Enhance Student Outcomes in a Didactic Program in Dietetics Foodservice Management Course}

\author{
Michael T. Holik \\ Scott Heinerichs \\ Jena Wood \\ West Chester University of Pennsylvania \\ United States
}

\begin{abstract}
Purpose: The purpose of this study was to describe student perceptions of their learning following experiential learning (EL) activities in a foodservice management course. Nutrition and dietetics education programs have a range of competencies students must learn and demonstrate throughout their curriculum. Learning styles differ amongst students and research has demonstrated they prefer to engage in EL (direct experience) activities to develop their knowledge. Foodservice management is one area of the curriculum that teaches students the basic functions of management; planning, organizing, directing, controlling, and staffing related to food, materials, facilities, and human resources. While this can be taught didactically, engaging in EL for this content may be a more valuable form of pedagogy to improve student understanding and use of content. Methods: After undergoing review and gaining approval from the Institutional Review Board, 196 nutrition and dietetic students from a regional comprehensive institution with an accredited undergraduate didactic program in dietetics were invited to participate in two experiential learning activities. At the conclusion of the activities, students completed an 8-question survey of their experiences. Results: Over $88 \%$ of students agreed EL activities promote better understanding of course content and $90 \%$ of students were in agreement that EL activities create an environment conducive to applying theory. Additionally, over $81 \%$ of students agreed that the activities encouraged the utilization of critical thinking skills, and $76 \%$ believed the activities promoted the value of teamwork and working independently. Finally, students were asked to respond to how the EL activity helped them understand course content and objectives. Two predominate themes emerged in the review of the open-ended responses. The first, EL helped connect and reinforce didactic theory to the real world ultimately assisting students to better prepare themselves for their career. The second focused on learning styles and students' appreciation for the non-traditional way of learning, outside the classroom, with hands-on application. Conclusions: The results of the study provide support for the use of EL activities in foodservice management courses in a dietetics program. Participation in EL activities helped students close the loop between theoretical and applied learning. EL helped the development and utilization of skills employers are seeking such as critical thinking, teamwork, and independence. EL allows students to be hands-on in their learning and engage in activities aligned with theory and content necessary to meet competencies for entry-level practice in the field. Future research should include other types of foodservice establishments where a registered dietitian is employed to determine if those environments have a positive impact on student learning.
\end{abstract}

Key Words: education, learning, experiential, dietetics, nutrition, management, foodservice 


\section{Introduction}

Dietetics education programs are required to cover a wide range of competencies from basic foundational knowledge to specific skills application. ${ }^{1}$ One content area within an undergraduate didactic dietetics program is Foodservice Management. Basic skills in this content area requires students to learn how to plan, organize, direct, control, and staff as each function relates to food, materials, facilities, and human resources. ${ }^{2}$ The traditional didactic style of teaching may not be the most effective method to develop these skills in students. ${ }^{1}$ This approach lacks the ability to deliver the high impact lessons that translate into the skills required for current industry standards. ${ }^{3}$

Engaging students in practical application has been demonstrated to create a conduit for knowledge, while closing the loop between theoretical and applied learning, which leads to better retention of content, social reinforcement, and improved employability. ${ }_{1,3-5}$ Immersing students in a practical environment teaches them how to be more engaged, become quick decision-makers, and experience situations that often cannot be simulated in a didactic setting. ${ }^{6}$ Experiential learning (EL) is a pedagogical approach that promotes learning by doing, whereby students are actively applying theories learned in the classroom in the community. EL activities have been shown to improve critical thinking skills in several allied health science programs. ${ }^{7}$ Engaging students using EL allows them to spend more meaningful time applying knowledge and practically figuring out tasks first-hand with a field expert present rather than when there is no field expert or instructor present to assist or answer questions. ${ }^{4}$ Additionally, EL also benefits communities where the activities take place as it enhances the social and professional networking, building stronger community relationships between novice students and experts. ${ }^{8}$

Experiential learning theory was introduced by educational psychologist David Kolb and involves four dimensions: concrete experience, reflection, nonfigurative conceptualization, and practical application. ${ }^{9}$ Each dimension is contained within the process of learning and development. ${ }^{9}$ Concrete experience involves hands-on application of tangible learning objectives and reflection includes connecting theoretical content applied practice followed by reflecting on how theory and application work together to aid the learning process. ${ }^{9}$ Nonfigurative conceptualization allows learners to observe and grasp lessons in a symbolic way and practical application transforms didactic learning theories into reality or realistic-simulation. ${ }^{9}$ This study was guided by the four dimensions of EL using the course-level student learning objectives as the guide. The objectives allowed a framework for students to observe and understand information that was taught didactically, apply content in practice by working with professionals in the field and their duties in a hospital and retail foodservice operation, and finally, student were asked to reflect on how the process impacted their learning. See Appendix A.

Research within nursing, occupational therapy, physical therapy, and nutrition have demonstrated that EL activities improve critical thinking and are perceived favorably by students. ${ }^{1,5,7,10,11}$ The purpose of this study was to examine students' perceptions of EL experiences in a foodservice management course in a nutrition and dietetics program.

\section{Theoretical Framework}

The main theory that guided this research was based on David Kolb's four dimensions of learning. ${ }^{9}$ Kolb's model focused on the linking of learning in four dimensions - concrete experience, reflection, nonfigurative conceptualization, and practical application.9,12 Together, these four dimensions of learning provide learners the ability to turn hypothesis into theory through the means of practical testing in a real-life experience and heightens a learner's capacity to troubleshoot, innovate, think outside the box when problemsolving or decision-making, and think strategically. EL creates opportunities for learners to examine and test interpersonal skills in a professional setting. ${ }^{13}$ In addition to Kolb's model, there are theorists' models such as John Dewey who placed emphasis on EL by dimensions, supporting Kolb's model. Brandon and Illeris noted the Dewey model guides learners through observation, recollection of knowledge, and judgment. ${ }^{12,15} \mathrm{As}$ in Kolb's dimensions of EL, there is a cross-context of content and socialization that translate experience into learning. ${ }^{8}$

\section{METHODOLOGY \\ Design}

This study was conducted utilizing action-based research, using qualitative and quantitative research as means of data collection. Action-based research is a reflective type of research that allows individuals to learn more and improve educational processes. ${ }^{15-}$

17 The EL activities introduced in this course were new, and the investigator sought to explore the impact they had on student learning. Action-based research is one of the few research methodologies which allows a primary investigator to also be a participant, which also means a higher level of commitment to remain objective. ${ }^{15-17}$

All students enrolled in a foodservice management course were required to participate in two experiential learning activities: one at a hospital and another at a retail foodservice operation. Each organization was provided specific learning objectives to guide their work with the students during the experiential activities (Appendix A). The objectives for the activities built upon course 
objectives allowing the students to apply their didactic knowledge in a practical way. All students spent a minimum of 2-hours outside of class time with the assigned registered dietitian of each organization, engaging in active learning exercises. After engaging in the experiential learning activities, all students were invited to participate in a post-experience survey that was reviewed and approved by the university's Institutional Review Board.

The data collection instrument was created exclusively for this study by the primary investigators. The instrument utilized was a Qualtrics ${ }^{\circledR}$ survey which allowed the primary investigators to collect quantitative and qualitative data. Questions in the survey were designed to collect before and after participating in experiential learning activities perceptions to help determine if experiential learning enhanced their academic experience. The survey consisted of both quantitative Likert questions and qualitative openended. See Appendix B.

\section{Data Collection}

The principal investigator and lead instructor of a foodservice management course developed a student perception of EL survey. The survey was initially piloted with four nutrition educators to determine face validity. Cronbach's Alpha was computed to demonstrate the psychometric testing of the tool as it relates to reliability and was .895. See Appendix B. All students enrolled in the course were asked to complete the online survey at the end of the semester using Qualtrics $₫$. The survey contained two sections: demographic information (i.e., gender, academic year, and age), and questions regarding their experience using a Likert Scale ( $1=$ strongly disagree, $5=$ strongly agree). Each Likert question included an open-ended response component for participants to report other perceptions relating to the question. See Appendix B.

\section{Data Analysis}

Descriptive statistics were calculated on the Likert scale items of the EL survey. To evaluate the open-ended questions, summative content analysis was used on all responses. ${ }^{19}$ Specifically, the three investigators individually reviewed survey results and analyzed for the appearance of keywords. Upon identification and frequency of keywords, alternative terms were discussed by the investigators who then identified alternative terms for words/content with significant frequency.

\section{RESULTS \\ Participants}

Upon review and approval from the institution's review board, undergraduate nutrition and dietetics students at a mid-sized regional comprehensive university were asked to participate in the study. Students were made aware of the study's purpose through an informed consent. Following the completion of the experiential learning activities, students were asked to complete a survey to understand their perceptions of the experience. While 285 students participated in the experiential learning activities at both the hospital and retail foodservice operation, only 196 consented and completed the survey. The participants in this study were $90.7 \%$ female; as a group, subjects ranged between 19 to 46 years old, with the majority (94.4\%) being between 20 to 23 years of age. Ninety-eight percent $(98.3 \%)$ of the participants were either at the level of a junior or senior in class standing.

Nutrition and dietetics students who were not enrolled in the foodservice management course were excluded. There was no risk to participants, so there were no other exclusion criteria because the course is a junior undergraduate-level, and none of the participants were minors. Additionally, students were able to choose whether they wanted to participate in the survey or not.

Data for both experiential learning activities were collected and reported jointly. Descriptive statistics for the 196 participant perceptions of EL survey are presented in Table 1 and Figure 1. Of the 196 who shared open-ended responses, results showed participants strongly agreed or agreed (88.95\%) that engaging in EL activities promotes better understanding of course material. Participants strongly agreed or agreed the activities encouraged the utilization of critical thinking $(81.77 \%)$ and promoted the values of teamwork and independence (76.8\%). Over ninety percent of participants also strongly agreed or agreed that the experience created an environment conducive for them to apply theory taught in the course. Overall, $68.7 \%$ ( $n=125)$ of students reported the experiences helped them make connections between theoretical course content and real-life application. Students were asked to rate their perception of the level of importance of EL using a five-point Likert scale before and after participating in EL activities. There was a $14 \%$ increase in the number of students who perceived engaging in EL activities was very important from pre to post and there was an overall decrease in students who felt it was moderately, slightly, and not important from pre to post (Figure 1). 
Table 1. Student Perceptions of EL

\begin{tabular}{|lccccc|}
\hline & $\begin{array}{c}\text { Strongly } \\
\text { Disagree }\end{array}$ & Disagree & $\begin{array}{c}\text { Neither agree } \\
\text { nor disagree }\end{array}$ & Agree & $\begin{array}{c}\text { Strongly } \\
\text { Agree }\end{array}$ \\
$\begin{array}{l}\text { Promotes better course } \\
\text { understanding }\end{array}$ & $1.66 \%$ & $2.76 \%$ & $6.63 \%$ & $49.17 \%$ & $39.78 \%$ \\
$\begin{array}{l}\text { Encourages utilization of } \\
\text { critical thinking }\end{array}$ & $2.21 \%$ & $4.97 \%$ & $11.05 \%$ & $49.17 \%$ & $32.60 \%$ \\
$\begin{array}{l}\text { Promotes value of teamwork } \\
\text { and working independently }\end{array}$ & $2.76 \%$ & $4.97 \%$ & $15.47 \%$ & $45.86 \%$ & $30.94 \%$ \\
$\begin{array}{l}\text { Creates an environment } \\
\text { conducive to apply theory }\end{array}$ & $1.10 \%$ & $2.76 \%$ & $5.52 \%$ & $48.62 \%$ & $41.99 \%$ \\
\hline
\end{tabular}

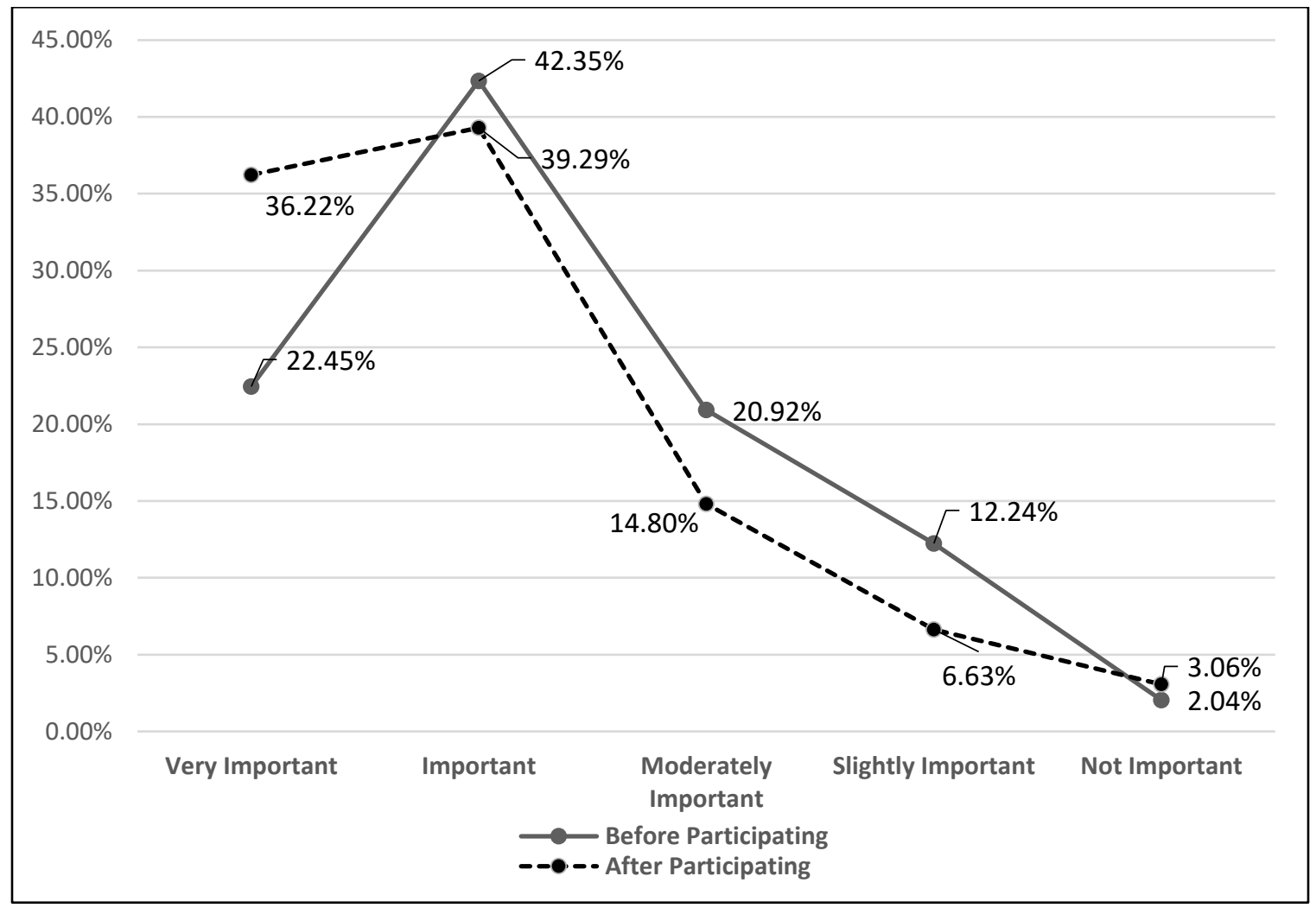

Figure 1. Student Perceptions of Importance of EL

The summative content analysis of the open-ended responses revealed more perspective when students were asked to respond to how the EL activity helped them understand course content and objectives. Two predominate themes emerged. The first centered on application of content and how EL helped connect and reinforce didactic theory to the real world ultimately assisting students with better preparedness for their future career. The second theme centered on learning styles focusing on students' appreciation for the non-traditional way of learning, outside the classroom, with hands-on application.

"EL should be embedded into more nutrition and dietetics courses. I think it's incredibly valuable to gain experience outside the classroom. We get so many examples and theory of what it will be like in the field, but very seldom get that actual experience until the internship or career. I think if more professors would allow for an experiential experience, students could determine if their major is the right fit for them far before they discover that it may not be and do something unrelated to their field." 
"After completing the EL activities, I realized how important and beneficial experiential learning can be." "It was interesting to see what someone can make of the degree we are receiving."

"Being able to take our knowledge in class and applying it hands on makes us better prepared people for the real world."

\section{DISCUSSION}

The purpose of this study was to examine students' perceptions of EL experiences in a foodservice management course in a nutrition and dietetics program. Student perceptions of EL experiences were identified. As in similar studies, students were able to apply course objectives in a practical and meaningful way by having the ability to shadow a registered dietitian.-9 During the experience, students were able to participate in a tray line service and patient meal delivery to gain firsthand knowledge of centralized distribution system, which could not be simulated didactically. Instead of theoretical learning about appropriate behavior for management/leadership and how to interact with patients, employees, and colleagues, participants were able to observe interactions and make connections with theoretical course lessons to real life situations. Didactically, students learned different ways hospital foodservice departments can be sustainable. Experientially, students were able to see their lessons of sustainable practices come to life at the hospital.

In the retail foodservice operation, participants were able to shadow a registered dietitian to apply course objectives practically as well. While both the hospital and retail were both foodservice operations, students were able to garner a completely different perspective of the role of a registered dietitian, exposing them to more career options. In the retail foodservice setting, students were able to apply didactic food safety and sanitation lessons by observing the various active foodservice areas of the operation. Students participated in food production, where they were able to again apply lessons of food safety and sanitation, recipe development, and nutrition analysis, and then apply menu labeling guidelines to the product they produced. As in the hospital experience, students observed management/leadership behaviors and interactions and learned the primary roles of a registered dietitian through shadowing. Overall, $68.7 \%(n=125)$ of students reported experiences helped them make connections between theoretical course content and real-life application, which is consistent with previous studies. ${ }^{1,3,7} \mathrm{~A}$ common benefit and reason for action-based research is when a participant wants to learn strategies or methods to improve their actions or reflect on and modify their practices.

\section{CONCLUSIONS}

The outcomes of this study echoed Kolb's dimensions of learning; concrete experience, reflection, nonfigurative conceptualization, and practical application. ${ }^{9,12}$ The majority of students in this study purported the EL activities helped them close the loop between theoretical and applied learning. ${ }^{1,3,4,5}$ Most students posited EL helped the development and utilization of critical thinking skills. ${ }^{7}$ While these activities were specifically created for hospital and retail foodservice settings, the study could be replicated for other types of foodservice establishments where a registered dietitian is employed.

This study gave the primary investigator, who also participated as the instructor of the course, the data necessary to determine if the EL activities enhance student outcomes. Based on the results of this study, the researcher was able to make these EL activities permanent components of the course curriculum. This study could be conducted again by separating the data collected from the experiences to analyze them independently to see if there are other patterns or themes. Additionally, the continued study could ask participants to take a pre and post-EL activity survey to give the researcher the ability to separate the data to run pre and post statistical analysis. 


\section{References}

1. Leveritt, M., Ball, L., \& Desbrow, J. (2013). Students' perceptions of an experiential learning activity designed to develop knowledge of food and food preparation methods. J Food Sci. Educ. 12(2013), 56-60.

2. ACEND. (2018). ACEND accreditation standards: For nutrition and dietetics didactic programs (DPD). Accessed 0619-19. https://www.eatrightpro.org/acend/accredited-programs/didactic-programs-in-dietetics

3. Rosier, J., Slade, C., Perkins, T., Baldwin, C., Coiacetto, E., Budge, T., \& Harwood, A. (2016). The benefits of embedding experiential learning in the education of planners. Plan. Pract. Res. 31(5), 486-499.

4. Handler, A., \& Duncan, K. (2006). Hammerhead shark research immersion program: Experiential learning leads to lasting educational benefits. J Sci Educ Technol 15(1), 9-16.

5. Smith, S., \& Crocker, A. (2017). Experiential learning in physical therapy education. Adv Med Educ Pract, 2017(8), 427- 433.

6. Grace, S., Innes, E., Patton, N., \& Stockhausen, L. (2017). Ethical experiential learning in medical, nursing and allied health education: A narrative review. Nurse Educ. Today 51(2017), 23-33.

7. Coker, J., \& Porter, D. (2016). Student motivations and perception across and within five forms of experiential learning. J Gen Educ 65(2), 138-156.

8. Harfitt, G., \& Chow, J. (2018). Transforming traditional models of initial teacher education through a mandatory experiential learning programme. Teach Teach Educ. 73(2018), 120-129.

9. Kolb, D. (1984). Experiential learning: Experience as the source of learning and development. Englewood Cliffs, $\mathrm{NJ}$ : Prentice Hall.

10. Pugsley, K., \& Clayton, L. (2003). Traditional lecture or experiential learning: Changing student attitudes. J Nurs Educ 42(11), 520-523.

11. Bohn, D., \& Schmidt, S. (2008). Implementing experiential learning activities in a large enrollment introductory food science and human nutrition course. J Food Sci 7(1), 5-13.

12. Illeris, K. (2007). What do we actually mean by experiential learning? Hum. Resour. Dev. Rev., March 2007(6), 84-95.

13. Rodriguez, C. (2018). A method for experiential learning and significant learning in architectural education via live projects. Arts Humanit. High. Educ., 17(3), 79-304.

14. Brandon, W. (2002). Experiential learning: A new research path to the study of journalism education. Journal. Mass Commun. Educ., 57(1), 59-66.

15. Henricks, C. (2017). Improving schools through action research: A reflective practice approach. Upper Saddle River, $\mathrm{NJ}$ : Pearson Education Inc.

16. Herr, K. \& Anderson, G. (2015). The action research dissertation: A guide for students and faculty. Thousand Oaks, CA: Sage Publications Inc.

17. Sagor, R. (2011). The action research guidebook: A four-stage process for educators and school teams. Thousand Oaks, CA: Corwin.

18. Creswell, J. (2014). Research design qualitative, quantitative, and mixed methods approaches. Thousand Oaks, CA: Sage Publication.

19. Hsieh, H., \& Shannon, S. (2005). Three Approaches to Content Analysis. Qual. Health Res., November 2005, 15(9), 1277-1288. 


\section{Appendix A}

\section{Hospital Experiential Objectives}

1. Students will work with or shadow a foodservice manager to learn about the Centralized and or Decentralized Service Distribution Systems.

2. Students will observe or learn about tray line production systems.

3. Student will learn about sustainability actions the hospital is taking in the foodservice operations.

4. Students will shadow a Catering Associate to learn about meal tray distribution.

5. Students will observe interactions between management and employees.

6. Students will be able to describe a Registered Dietitian's primary role in hospital foodservice.

\section{Retail Foodservice Objectives}

\section{Didactic Objectives}

1. Students will learn about sustainability actions the supermarket is taking in the foodservice operations.

2. Students will work with or shadow a retail dietitian to learn about the food production and schedule in a retail grocery setting.

3. Students will be able to describe the federal menu labeling law and how it relates to supermarkets and food production.

4. Students will learn principles of food safety and sanitation in the supermarket.

5. Through observation, students will implement knowledge of federal menu labeling laws as they relate to a supermarket.

\section{Experiential Objectives}

1. Students will apply principles of food safety and sanitation by participating in a retail dietitian facilitated hands-on demonstration.

2. Students will be able to describe a registered dietitian's primary role in retail and grocery store foodservice.

3. Students will observe interactions between registered dietitian, management, or other employees.

\section{Appendix B}

1. You recently completed an experiential learning activity in your foodservice management course to better understand the foodservice aspect of a registered dietitian's daily job duties. The purpose of this survey is to understand your perceptions of this experience. Experiential learning is not easily defined and while it does not have a universal definition, it is commonly defined as an applied style of learning. How do you define experiential learning?
a. Applied Learning
b. Learning that takes place outside classroom
c. Applied Practice
d. Supplemental learning to theoretical learning

2. Prior to participating in the experiential learning activity, did you know what experiential learning was?
a. Yes
b. No

3. Rate the following elements of the experiential learning experience.

a. Prior to participating in the experiential learning activity, how important do you feel the experience was to your learning?

i. Not important, slightly important, moderately important, important, very important

b. After participating in the experiential learning activity, how important do you feel the experience was to your learning?

i. Not important, slightly important, moderately important, important, very important

c. Briefly describe your responses.

4. Rate the following element of the experiential learning experience.

a. How valuable was the experiential learning in helping you understand course content and objectives?

i. Not valuable, limited value, average value, valuable, very valuable

b. Briefly describe your responses.

5. Rate the following element of the experiential learning experience. 
a. How effective was the experiential learning activity in allowing you to apply course theory into practice?

i. Very ineffective, ineffective, average, effective, very effective

b. Briefly describe your responses.

6. Rate the following elements of experiential learning.

a. Promotes better course understanding

i. Strong disagree, disagree, neither, agree or disagree, agree, strongly agree

b. Encourages the utilization of critical thinking

i. Strong disagree, disagree, neither, agree or disagree, agree, strongly agree

c. Promotes the value of teamwork and working independently

i. Strong disagree, disagree, neither, agree or disagree, agree, strongly agree

d. Creates an environment conducive to apply theory

i. Strong disagree, disagree, neither, agree or disagree, agree, strongly agree

e. Briefly describe your responses. 